\title{
Developmental and Target-Dependent Regulation of Vesicular Glutamate Transporter Expression by Dopamine Neurons
}

\author{
Jose Alfredo Mendez, ${ }^{1,3}$ Marie-Josée Bourque, ${ }^{1,3}$ Gregory Dal Bo, ${ }^{1,3}$ Mathieu L. Bourdeau, ${ }^{2,3}$ Marc Danik, ${ }^{4}$ \\ Sylvain Williams, ${ }^{4}$ Jean-Claude Lacaille, ${ }^{2,3}$ and Louis-Eric Trudeau ${ }^{1,2,3}$ \\ ${ }^{1}$ Department of Pharmacology, ${ }^{2}$ Department of Physiology, and ${ }^{3}$ CNS Research Group, Faculty of Medicine, University of Montreal, Montreal, Quebec, \\ Canada H3C 3J7, and ${ }^{4}$ Department of Psychiatry, Douglas Hospital Research Center, McGill University, Montreal, Quebec, Canada H4H 1R3
}

\begin{abstract}
Mesencephalic dopamine (DA) neurons have been suggested to use glutamate as a cotransmitter. Here, we suggest a mechanism for this form of cotransmission by showing that a subset of DA neurons both in vitro and in vivo expresses vesicular glutamate transporter 2 (VGluT2). Expression of VGluT2 decreases with age. Moreover, when DA neurons are grown in isolation using a microculture system, there is a marked upregulation of VGluT2 expression. We provide evidence that expression of this transporter is normally repressed through a contact-dependent interaction with GABA and other DA neurons, thus providing a partial explanation for the highly restricted expression of VGluT2 in DA neurons in vivo. Our results demonstrate that the neurotransmitter phenotype of DA neurons is both developmentally and dynamically regulated. These findings may have implications for a better understanding of the fast synaptic action of DA neurons as well as basal ganglia circuitry.
\end{abstract}

Key words: VGluT2; VTA; substantia nigra; cotransmission; dopamine; glutamate

\section{Introduction}

Neurons have long been known to synthesize and release peptides as cotransmitters. Although a number of cases have been described (Holton, 1959; Schwarzer and Sperk, 1995; Jonas et al., 1998; Gutierrez, 2000; Yang et al., 2002; Borodinsky et al., 2004; Trudeau, 2004; Gillespie et al., 2005), the ability of some of these neurons to release two classical neurotransmitters has attracted less attention. The recent characterization of vesicular glutamate transporters 1-3 (VGluT1-VGlutT3) has renewed attention on neuronal populations that release glutamate (Trudeau, 2004). Interestingly, whereas VGluT1 and VGluT2 were found to be present in most well known glutamatergic neuronal populations (Fremeau et al., 2001), VGluT3 was reported to be expressed in neurons releasing the neurotransmitters serotonin or acetylcholine (Fremeau et al., 2002; Gras et al., 2002; Schafer et al., 2002; Herzog et al., 2004), thus suggesting that these neurons use glutamate as cotransmitter.

Physiological data suggest that DA neurons may also use glutamate as a cotransmitter. Electrical stimulation of the ventral

Received March 27, 2008; revised April 29, 2008; accepted May 5, 2008.

This work was supported by a grant from National Alliance for Research on Schizophrenia and Depression and a Fonds de la Recherche en Santé Québec (FRSQ) senior investigator grant (L.-E.T.), an FRSQ infrastructure grant to the Groupe de Recherche sur le Système Nerveux Central (GRSNC) (L.-E.T.), and a postdoctoral fellowship from the GRSNC (J.A.M.). J.-C.L. is the recipient of a Canada Research Chair in Cellular and Molecular Neurophysiology. We thank Stephanie Fulton for her comments on this manuscript.

Correspondence should be addressed to Dr. Louis-Eric Trudeau, Department of Pharmacology, Faculty of Medicine, University of Montreal, C.P. 6128, Succursale Centre-Ville, Montreal, Quebec, Canada H3C 3J7. E-mail: louis-eric.trudeau@umontreal.ca.

DOI:10.1523/JNEUROSCI.1331-08.2008

Copyright $\odot 2008$ Society for Neuroscience $\quad$ 0270-6474/08/286309-10\$15.00/0 tegmental area (VTA) induces fast glutamate-mediated EPSCs in medium spiny neurons of the nucleus accumbens (nAcc) (Chuhma et al., 2004) as well as in prefrontal cortex (PFC) neurons (Lavin et al., 2005). In addition, in vitro data demonstrated that cultured mesencephalic DA neurons have the capacity to establish glutamate-mediated synaptic contacts (Sulzer et al., 1998; Bourque and Trudeau, 2000; Joyce and Rayport, 2000; Rayport, 2001). Although these findings imply the expression of one or more of the VGluTs in DA neurons, this has not yet been examined with sufficient detail and very little information about their regulation has been obtained. Initial in situ hybridization experiments failed to identify expression of the VGluTs in DA neurons (Fremeau et al., 2001; Herzog et al., 2004). However, one study reported expression of VGluT3 in the VTA and substantia nigra (SN) (Fremeau et al., 2002). In relative contradiction, the majority of mesencephalic DA neurons in microculture selectively express VGluT2 (Dal Bo et al., 2004). Finally, in a recent in situ hybridization study performed in adult rats, expression of VGluT2 was reported in a subset of DA neurons of the rostral linear (RLi), interfascicular (IF), and caudal linear nuclei (CLi) (Kawano et al., 2006), cell groups that, with the VTA, are components of the A10 catecholaminergic neurons. In a similar study, DA neurons coexpressing VGluT2 mRNA were reported to be very rare $(\sim 0.1 \%)$ in the VTA of adult rats (Yamaguchi et al., 2007).

To extend these initial observations, we examined the expression of VGluT transcripts in VTA/SN DA neurons using singlecell reverse transcriptase (RT)-PCR, thus providing higher sensitivity of detection. In the context of recent studies demonstrating 
that the transmitter phenotype of neurons can be plastic (GomezLira et al., 2005; Trevino and Gutierrez, 2005), we also investigated the regulation of VGluT2 expression. Our results show that VGluT2 is the only VGluT expressed in VTA/SN DA neurons in vivo. Moreover, we find that its expression decreases with age and is negatively regulated through a contact-dependent signal provided by GABA and DA neurons, thus providing an explanation for the limited expression of VGluT2 in DA neurons in vivo.

\section{Materials and Methods}

Animals. Unless otherwise stated, experiments were performed using the tyrosine hydroxylase green fluorescent protein (TH-GFP) transgenic mouse line TH-EGFP/21-31, which carries the enhanced GFP (EGFP) gene under the control of the TH promoter (Sawamoto et al., 2001; Matsushita et al., 2002). In these mice, the vast majority of GFPexpressing cells are catecholaminergic neurons, although ectopic expression of GFP is also found in a minority of neurons, mostly at younger ages [younger than postnatal day 15 (P15)], possibly because of the fact that some elements are missing from the TH promoter used (Sawamoto et al., 2001; Matsushita et al., 2002). As a control, we used wild-type mice of the same genetic C57BL/6 background (Charles River). Experiments involving the VGluT2-EGFP mice were performed using the strain STOCK $\operatorname{Tg}$ (Slc17a6-EGFP)115Gsat (identification number 11835-UCD) obtained from the Mutant Mouse Regional Resource Center (MMRRC) (donated to the MMRRC by the National Institute of Neurological Disorders and Stroke-funded GENSAT BAC transgenic project, Dr. Nathaniel Heintz, The Rockefeller University, New York, NY). This strain has an FVB/N Swiss-Webster hybrid background carrying multiple randomly inserted copies of a modified bacterial artificial chromosome (BAC) in which the EGFP reporter gene together with an exogenous polyadenylation signal replaces the VGluT2 coding sequence but keeps the VGluT2 promoter (Gong et al., 2003).

Tissue processing. Coronal slices ( $1 \mathrm{~mm}$ thick) containing both the VTA and SN in which the medial nuclei (RLi, IF, and CLi) were eliminated were obtained from $\mathrm{P} 0$ and P14-P15 animals. For newborn mice (P0), tissue collection was preceded by cryoanesthesia and decapitation. The tissue was collected in ice-cold dissociation solution containing (in mм) $90 \mathrm{Na}_{2} \mathrm{SO}_{4}, 30 \mathrm{~K}_{2} \mathrm{SO}_{4}, 5.8 \mathrm{MgCl}_{2}, 0.25 \mathrm{CaCl}_{2}, 10$ HEPES, 20 glucose, and $0.001 \%$ phenol red, pH 7.4. For P14 and P45 mice, animals were anesthetized with Halothane (Sigma-Aldrich) and decapitated, brains were collected immediately in oxygenated saline solution containing (in mм) $130 \mathrm{NaCl}, 20 \mathrm{NaHCO}_{3}, 1.25 \mathrm{KH}_{2} \mathrm{PO}_{4}, 1.3 \mathrm{MgSO}_{4}, 3 \mathrm{KCl}, 10$ glucose, and $1.2 \mathrm{CaCl}_{2}$, and the slices were prepared. All animal handling procedures were approved by the University of Montreal Animal Ethics Committee.

Acutely dissociated neurons. Tissue obtained as described above was processed as follows: for $\mathrm{P} 0$ animals, the tissue was treated with papain (Worthington Biochemical) for $20 \mathrm{~min}$ at $37^{\circ} \mathrm{C}$, then triturated by several passages through glass pipettes of decreasing diameter to obtain a mesencephalic cell suspension (Kay and Wong, 1986; Bourque and Trudeau, 2000). For $\mathrm{P} 45$ animals, the tissue was treated for $30 \mathrm{~min}$ at $30^{\circ} \mathrm{C}$ with trypsin in oxygenated $\left(100 \% \mathrm{O}_{2}\right)$ piperazine- $N$ - $N^{\prime}$-bis (2-ethane sulfonic acid) (PIPES) buffer containing (in mM) $115 \mathrm{NaCl}, 5 \mathrm{KCl}, 1 \mathrm{CaCl}_{2}, 4$ $\mathrm{MgCl}_{2}, 25$ glucose, and 20 PIPES, pH 7.0. Trypsin was subsequently neutralized by two rinses with $10 \%$ fetal bovine serum (FBS) in oxygenated PIPES buffer, the tissue was left to stabilize for $1.25 \mathrm{~h}$ at room temperature in oxygenated PIPES buffer, and then triturated as for P0 animals to obtain the mesencephalic cell suspension. For P14 animals, the procedure was the same as for $\mathrm{P} 45$ except for the composition of the PIPES buffer (in mM): $120 \mathrm{NaCl}, 2 \mathrm{KCl}, 0.5 \mathrm{CaCl}_{2}, 1 \mathrm{MgCl}_{2}, 25$ glucose, and 20 PIPES, pH 7.0 (Danik et al., 2003).

Cell sorting. The different mesencephalic cell suspensions obtained as described above were centrifuged in a differential gradient to eliminate dead cells and debris. Thereafter, living cells were resuspended carefully in PBS with $1 \%$ FBS and injected into a BD FACSAria (BD BioSciences) flow cytometer/cell sorter. GFP-positive cells were purified by sorting them against fluorescence profiles of mesencephalic cell suspensions prepared from wild-type mice and discrimination of dead cells was done with propidium iodide. The fluorescence profile of sorted cells showed that the GFP intensity varied up to two orders of magnitude (from 1000 to 100,000 fluorescence units), which we believe reflects the variability in TH expression by DA neurons. There was thus no selection bias toward highly expressing cells in the fluorescence-activated cell sorting (FACS) experiments.

Cell culture. Primary cultures of mesencephalic DA neurons were prepared according to previously described protocols (Segal et al., 1998; Sulzer et al., 1998; Bourque and Trudeau, 2000; Jomphe et al., 2005). Mesencephalic cell suspension or FACS-purified cells were plated onto either microislands (microculture) or monolayers (standard cultures) of astrocytes. The latter were established using cortical astrocytes grown on collagen/poly-L-lysine precoated coverslips. For microcultures (Segal et al., 1998), collagen was sprayed onto agarose-covered coverslips to establish small microislands of substrate suitable for the growth of single neurons or small groups of neurons.

RNA extraction and multiplex RT-PCR. Total RNA was extracted from FACS-purified cells as well as from tissues used as controls and standard primary culture coverslips by using TRIzol (Invitrogen) according to manufacturer's protocol. To ensure the purification of RNA from FACSpurified cells, $5 \mu \mathrm{g}$ of glycogen (Invitrogen) was added. In all cases, total RNA was dissolved in diethylpyrocarbonate-treated water and stored at $-80^{\circ} \mathrm{C}$ until use. cDNA synthesis was performed for $1 \mathrm{~h}$ using $0.5 \mathrm{~mm}$ deoxynucleotide triphosphate (dNTP) mix (Qiagen), $2.5 \mu \mathrm{M}$ random hexamers (RHs; Applied Biosystems), $1 \mu \mathrm{g}$ of total RNA, 10 mM DTT, 40 U RNaseOUT, 200 U Moloney-murine leukemia virus (M-MLV) RT (Invitrogen), $50 \mathrm{~mm}$ Tris- $\mathrm{HCl}, 75 \mathrm{~mm} \mathrm{KCl}$, and $3 \mathrm{~mm} \mathrm{MgCl}_{2}$, $\mathrm{pH}$ 8.3. RT enzyme was denatured and the cDNAs stored at $-80^{\circ} \mathrm{C}$ until use. PCRs were performed using $20 \%$ of the RT reaction, $1.5 \mathrm{~mm} \mathrm{MgCl}_{2}, 0.5 \mathrm{~mm}$ dNTP mix, 10 pmol of each primer, 5 units Taq-DNA polymerase (Qiagen), $20 \mathrm{~mm}$ Tris- $\mathrm{HCl}$, and $50 \mathrm{~mm} \mathrm{KCl}, \mathrm{pH}$ 8.3. A semiquantitative RTPCR method was standardized to measure relative levels of VGluT2 and TH by normalizing to $\beta$-actin levels.

Multiplex single-cell RT-PCR. Samples were collected as follows. (1) To prepare freshly dissociated cells, the mesencephalic cell suspension was plated on polyethyleneimine (PEI)-coated coverslips mounted into an electrophysiology recording chamber. Cells were left to adhere at room temperature for $15 \mathrm{~min}$ and then washed under perfusion with oxygenated PIPES-buffer to remove nonattached cells and debris. (2) For cultured neurons, GFP-positive DA neurons cultured on glass coverslips were mounted into a recording chamber and kept under perfusion. (3) For acute brain slices, mice were deeply anesthetized with halothane and decapitated. The brain was removed quickly and placed in ice-cold artificial CSF (ACSF) [containing (in mM) $125 \mathrm{NaCl}, 25 \mathrm{NaHCO}_{3}, 2.5 \mathrm{KCl}$, $1.25 \mathrm{NaH}_{2} \mathrm{PO}_{4}, 2 \mathrm{CaCl}_{2}, 2 \mathrm{MgCl}_{2}$, and 23 glucose] saturated with $95 \%$ $\mathrm{O}_{2}-5 \% \mathrm{CO}_{2}$. Using a vibrating microtome (Leica), 250- $\mu$ m-thick horizontal brain slices were cut in ice-cold oxygenated ACSF and left to recuperate in ACSF at room temperature $\left(20-22^{\circ} \mathrm{C}\right)$ until use.

In all cases, GFP-expressing cells were collected individually under RNase-free conditions by using autoclaved borosilicate patch pipettes; each cell was collected by applying light negative pressure to the pipette. GFP-expressing cells were selected randomly so as to avoid a selection bias in favor of highly GFP-expressing cells. In support of this, an analysis of TH expression by DA neurons in single-cell RT-PCR experiments showed a large variance in signal intensity (results not shown). For freshly dissociated cells and cultured neurons, coverslips were mounted in a recording chamber fixed to the stage of an inverted Nikon Eclipse TE-200 microscope equipped with epifluorescence. Coverslips were kept under perfusion of physiological saline solution [containing (in mM) 140 $\mathrm{NaCl}, 5 \mathrm{KCl}, 2 \mathrm{MgCl}_{2}, 2 \mathrm{CaCl}_{2}, 10$ HEPES, 10 glucose, and 6 sucrose, $\mathrm{pH}$ 7.35 and $305 \mathrm{mOsm}$ ] using a gravity flow system $(1 \mathrm{ml} / \mathrm{min})$; no intracellular pipette solution was used. Acute brain slices were placed in a custom Plexiglas chamber and viewed with an upright microscope (Zeiss Axioskop) equipped with Hoffmann optics (Modulation Optics), a longrange water-immersion objective $(40 \times)$, and an infrared video camera (Cohu). GFP-expressing neurons from the SN and VTA were identified using an epifluorescence Fluoarc system (Zeiss) and selected for patchclamp recordings. An Axopatch 200B amplifier (Molecular Devices) connected to a Pentium-based computer using pClamp 9.0 (Molecular 
Devices) was used to monitor seal formation and rupture. Sterile patch pipettes (1.0 mm outer diameter, $2-5 \mathrm{M} \Omega$ ) were filled with a sterilefiltered solution containing (in mM) $130 \mathrm{CsMeSO}_{3}, 5 \mathrm{CsCl}, 2 \mathrm{MgCl}_{2}, 5$ diNa-phosphocreatine, 10 HEPES, 2 ATP-Tris, and 0.4 GTP-Tris, 290 mOsm. During whole-cell recordings, the biophysical properties of the neurons were monitored and membrane potential was held at $-60 \mathrm{mV}$ in voltage-clamp mode. Intracellular content was aspirated by applying negative pressure to the patch pipette and changes in leak current were monitored. To monitor the position of collected cells, neighboring neurons were loaded with biocytin and immunohistochemistry was performed against TH and biocytin. Once samples were collected, the content of the pipette was transferred immediately into a prechilled $200 \mu \mathrm{l}$ tube containing $6 \mu \mathrm{l}$ of a freshly prepared solution of $20 \mathrm{U}$ of RNaseOUT and $8.3 \mathrm{~mm}$ DTT (Invitrogen) and then frozen on dry ice until use. Frozen samples were thawed on ice and subjected to the RT reaction as describe above for total RNA but using $1.25 \mu \mathrm{M}$ RHs, $100 \mathrm{U}$ M-MLV RT and an additional $20 \mathrm{U}$ of RNaseOUT. A first round of PCR was done as mentioned above but using the entire RT reaction and 25 cycles with $55^{\circ} \mathrm{C}$ of annealing temperature. A second round of PCR was done using $10 \%$ of first PCR and 30 cycles. PCRs were resolved in 1.5\% agarose gels.

Primers. Primers (custom made by Alpha-DNA) were designed to bind to nonhomologous areas and not to interact with the other primers in the multiplex PCR. It was not necessary to perform nested PCRs in the second round of PCR except for TH. In addition, a second set of primers for VGluT2 was used to corroborate our findings (results not shown). Primers were designed based on sequences deposited in the Entrez Nucleotides database (www.ncbi.nlm.nih.gov) and tested using the appropriate positive and negative controls. Right primers are followed by left primers: GFP, $5^{\prime}$-aagttcatctgcaccaccg- $3^{\prime}$ and $5^{\prime}$-tgctcaggtagtggttgtcg- $3^{\prime}$; $\beta$-actin, $5^{\prime}$-ctcttttccagccttccttctt- $3^{\prime}$ and $5^{\prime}$-agtaatctccttctgcatcctgtc- 3 ; $\mathrm{TH}, 5^{\prime}$-gttctcaacctgctcttctcctt- $3^{\prime}$ and $5^{\prime}$-ggtagcaatttcctcctttgtgt- $3^{\prime}$; THnested, $5^{\prime}$-gtacaaaaccctcctcactgtctc- $3^{\prime}$ and $5^{\prime}$-cttgtattggaaggcaatctctg- $3^{\prime}$; GAD-67, 5' -atatcattggtttagctggtgaatg- $3^{\prime}$ and $5^{\prime}$-gtgactgtgttctgaggtgaagag- $3^{\prime}$; GFAP, $5^{\prime}$-agaagctccaagatgaaaccaa- $3^{\prime}$ and $5^{\prime}$-ctttaccacgatgttcctcttga-3'; VGluT1, 5' -cgtcacataatgtccactaccaac- $3^{\prime}$ and $5^{\prime}$-cctcgtcctccatttcactttc-3'; VGluT2, 5'-atctacagggtgctggagaagaa- $3^{\prime}$ and $5^{\prime}$ gatagtgctgttgttgaccatgt- $3^{\prime}$; VGluT3, $5^{\prime}$-gggaccaatgaagaggaagatg- $3^{\prime}$ and $5^{\prime}$-atttctggtttcccatccacatac-3; VGluT2b 5'-ggggaaagaggggataaagaa-3' and $5^{\prime}$-tggctttctccttgataactttg-3. The VGluT2 upper primer was designed to bind to the boundaries between two exons, therefore, the signal we obtained could not come from genomic DNA. Each time we used VGluT2 primers, VGluT1 and VGluT3 primers were also used. In addition, the $\beta$-actin primers were designed to distinguish between mRNA and genomic DNA. Samples in which genomic $\beta$-actin PCR product was detected were discarded. The identity of PCR products was confirmed by sequencing.

Western blot. FACS-purified cells were lysed and boiled for $5 \mathrm{~min}$ in Laemmli's sample buffer. Proteins were resolved in 10\% SDS-PAGE and transferred onto nitrocellulose membranes. Membranes were incubated in Tris-buffered saline containing 5\% dried skimmed milk and $0.1 \%$ Tween 20 for $1 \mathrm{~h}$ to block nonspecific protein binding sites. Membranes were then incubated overnight at $4^{\circ} \mathrm{C}$ with the primary antibodies diluted in blocking solution. The signal of the secondary horseradish peroxidaselabeled antibodies (Jackson ImmunoResearch) was detected by chemiluminescence (Pierce). Primary antibodies used were: rabbit anti-VGluT2 (Synaptic Systems) and mouse anti- $\beta$-actin (Abcam).

Immunocytochemistry. Cultures were fixed with $4 \%$ paraformaldehyde (PFA) in PBS, permeabilized, and nonspecific binding sites blocked. A rabbit anti-VGluT2 antibody (Synaptic Systems) was used in combination with a mouse monoclonal anti-TH antibody (Sigma-Aldrich) for double immunodetection assays to determine the percentages of DA neurons expressing VGluT2. Percentages of GFP/TH positive cells were evaluated by double immunodetection using the anti-TH mentioned above in combination with a rabbit anti-GFP (Abcam). Primary antibody visualization was performed using the appropriated goat Alexalabeled secondary antibodies (Invitrogen). For triple immunodetection experiments, the anti-VGluT2 antibody was used in combination with a goat anti-TH antibody (Santa Cruz Biotechnology) and a mouse monoclonal anti-GABA antibody (Sigma-Aldrich). Primary antibody visual- ization was done by using the appropriate donkey Alexa-labeled secondary antibodies (Invitrogen). For the experiments with VGluT2-EGFP mice, animals were transcardially perfused with $4 \%$ PFA and $40-\mu \mathrm{m}$ thick mesencephalic coronal sections prepared. Sections were permeabilized and nonspecific binding sites blocked. Double immunodetection assays of GFP and TH was performed as mentioned above. In all cases, images were acquired using a Hamamatsu Orca-II digital-cooled CCD camera and an Inovision workstation using the Isee software suite.

Striatal lesions. P10 TH-GFP littermates were cryoanesthetized and placed in a stereotaxic apparatus. Unilateral injections of $20 \mathrm{nmol} / 500 \mathrm{nl}$ of the excitotoxin quinolinic acid (QA) (Sigma-Aldrich) were performed in the dorsomedial region of the right striatum according to the following coordinates: $1.0 \mathrm{~mm}$ anterior to bregma, $2.0 \mathrm{~mm}$ lateral to midline, and $2.6 \mathrm{~mm}$ ventral to the pial surface. Five days after lesion, neurons were acutely dissociated as described previously, a mesencephalic cell suspension obtained and freshly dissociated cells collected to perform single-cell RT-PCR assays. Sham animals received an injection of the vehicle in the same volume, under identical conditions. The striatal lesion was assessed by immunohistochemistry against GABA and S100 to detect the loss of GABA cell bodies and processes as well as changes in the astrocyte population.

Statistics. Data shown throughout are the mean \pm SD of at least three experiments. Statistically significant differences among conditions were analyzed either by a one way ANOVA with Dunnett's multiple comparison test or with a $t$ test, as required.

\section{Results \\ Dopamine neurons express VGluT2 but not VGluT1 nor VGluT3}

As a first evaluation of the expression of VGluTs in DA neurons, we performed semiquantitative RT-PCR assays using RNA obtained from freshly dissociated VTA/SN DA neurons purified by FACS from TH-GFP transgenic mice (Fig. 1A). We found that FACS-purified DA neurons obtained from P0 to P45 mice express VGluT2 mRNA (Fig. $1 B$ ). Moreover, there was an agedependent decrease in the relative levels of VGluT2 mRNA (Fig. $1 B, C)$. Under our conditions, we were unable to find any expression of neither VGluT1 nor VGluT3, even when we increased the number of cycles in the RT-PCR (Fig. $1 B$ ). In line with a previous report (Matsushita et al., 2002), we detected a modest relative increase of TH mRNA level as a function of age (Fig. 1C). The efficiency of the FACS-purification procedure was evaluated by double immunocytochemistry; the majority of GFP-expressing cells collected were $\mathrm{TH}+$ neurons $(\mathrm{P} 0,93.7 \pm 2.0, n=4$; $\mathrm{P} 14$, $95.5 \pm 1.6, n=3$; P45, $95.3 \pm 1.5, n=3)$. No expression of the phenotypic markers for GABAergic neurons (GAD-67) or astrocytes (GFAP) was detected under the same conditions used to detect VGluT2 (Fig. 1D).

To confirm the selective expression of VGluT2 in DA neurons and to rule out the possibility that VGluT2 mRNA was attributable to contamination, we performed multiplex single-cell RTPCR experiments using freshly dissociated GFP-expressing neurons collected from the VTA/SN region of $\mathrm{P} 0$ and $\mathrm{P} 45$ mice. We again detected no expression of VGluT1 or VGluT3 in individual DA neurons (Fig. $2 A, B$ ). Interestingly, VGluT2 mRNA was found in $25 \%$ of DA neurons at P0 and in 14\% of DA neurons at $\mathrm{P} 45$, thus confirming an age-dependent decrease in expression. Additionally, in line with previous reports, at P0 but not at P45, we detected a small subset $(12 \%)$ of TH-negative neurons that expressed VGluT2 mRNA (Fig. 2A). Summary data for VGluT isoform expression in single acutely dissociated DA neurons is presented in Table 1 (top two rows).

Positive controls were obtained to evaluate our ability to detect VGluT1 and VGluT3 transcripts in single neurons by collect- 

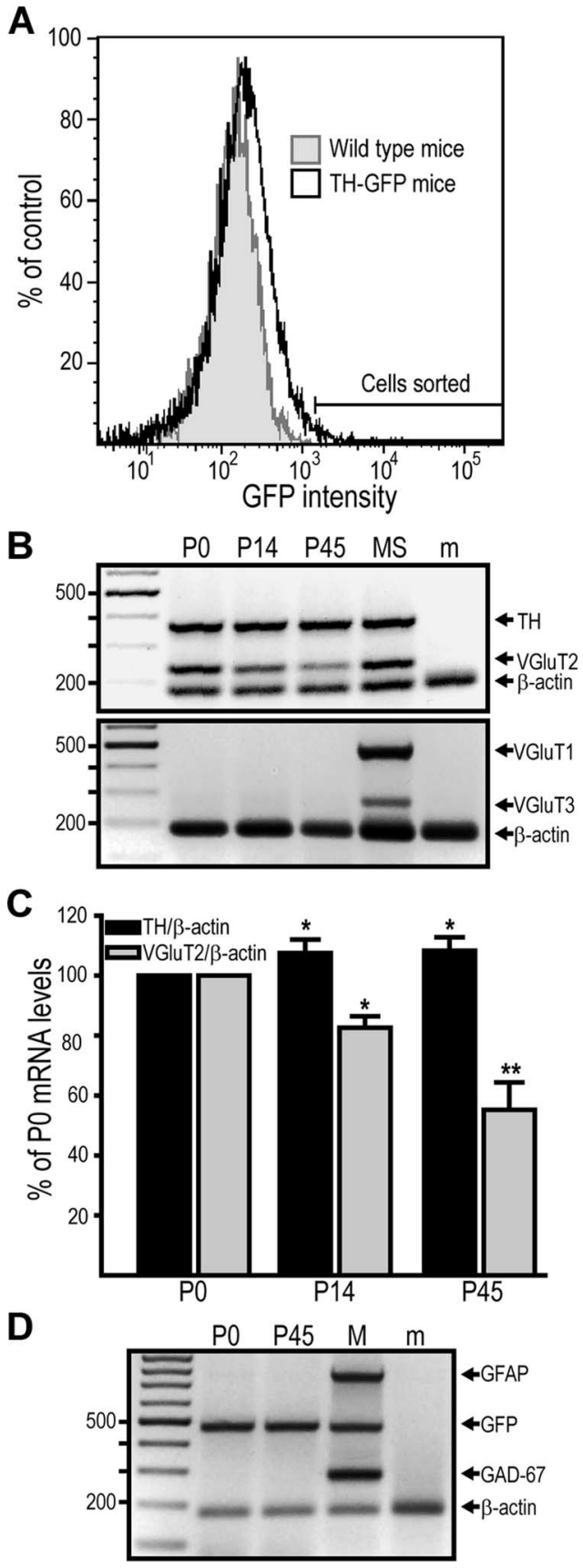

Figure 1. VGluT2 mRNA expression in FACS-purified DA neurons. Freshly dissociated GFPexpressing neurons from both VTA and SN of P0, P14, and P45 TH-GFP mice were purified by FACS and subjected to semiquantitative multiplex RT-PCR. $A$, Fluorescence profile of a mesencephalic cell suspension prepared from TH-GFP mice (white) compared with a wild-type cell suspension (gray). $\boldsymbol{B}$, Expression of $\beta$-actin, VGluT2, and TH mRNA (top), as well as VGluT1 and VGluT3 alongside $\beta$-actin (bottom) to ascertain the presence of mRNA. Note that the number of cycles was augmented in the bottom to 39 instead of 27 as in the top. MS, Whole mesencephalon plus striatum, used as positive control (Danik et al., 2003, 2005); m, muscle, negative control (Aihara et al., 2000). C, Densitometric analysis of the results presented in the top panel of $\boldsymbol{B} .{ }^{*} p<0.05$; ${ }^{* *} p<0.01$ versus $P 0$. $\boldsymbol{D}$, The purity of FACS-purified neurons was assessed by RT-PCR for GFAP and GAD-67 as negative controls and GFP as a positive control. M, Whole mesencephalon. Error bars indicate SD.

ing additional neurons from the cerebral cortex (VGluT1) and from raphe nuclei in the caudal midbrain (VGluT3) (Fig. 2C).

We next evaluated whether VGluT2 protein, in addition to mRNA, is produced by DA neurons. Using immunocytochemistry in freshly dissociated neurons we found that at P0 and P45,
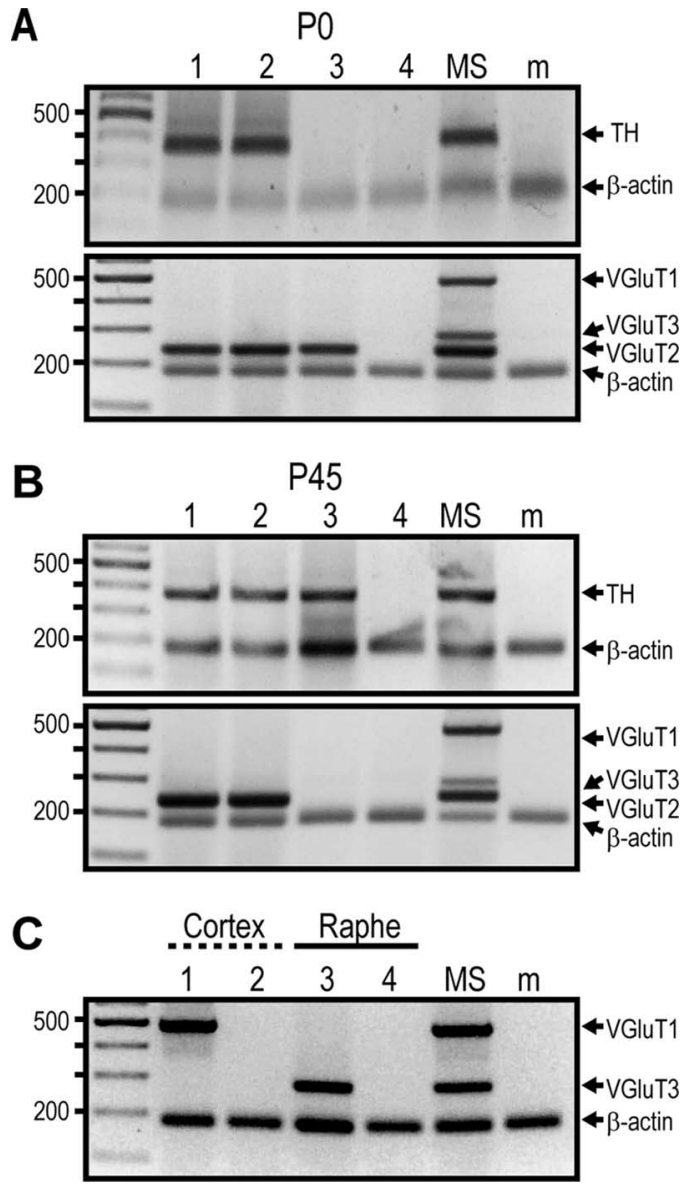

Figure 2. $\quad A, B$, Single-cell RT-PCR demonstrates the selective expression of VGluT2 in freshly dissociated DA neurons. Expression profile of representative freshly dissociated GFP-expressing neurons collected individually from PO $(\boldsymbol{A})$ and P45 (B) TH-GFP mice. The presence of TH mRNA was first verified to ascertain their dopaminergic phenotype, whereas the presence of $\beta$-actin mRNA was used to confirm the presence of intact mRNA and to test for genomic DNA contamination (top). The expression of the three VGluTs was subsequently measured alongside $\beta$-actin (bottom). $\boldsymbol{A}$, Cells 1 and 2 are DA neurons expressing VGluT2 mRNA, whereas cell 3 is a purely glutamatergic neuron and cell 4 is a non-TH, nonglutamatergic neuron. $\boldsymbol{B}$, Cells 1 and 2 are DA neurons containing VGluT2 mRNA, whereas cell 3 is a DA neuron that did not contain VGluT2 mRNA. Finally, cell 4 is a neuron expressing neither TH nor VGluT2 mRNA. C, Freshly dissociated single neurons collected from cortex (cells 1-2) and raphe nucleus (cells 3-4) were used as positive controls for VGluT1 and VGluT3, respectively. A VGluT-negative neuron from each nucleus is also shown. MS, Mesencephalon plus striatum; $m$, muscle.

$17.6 \pm 3.1 \%$ (534 of 3406$)$ and $8.7 \pm 2.3 \%$ (209 of 2923 ) of TH+ neurons were also immunopositive for VGluT2, respectively (Fig. 3A). Using Western blot analysis of protein extracts prepared from FACS-purified DA neurons, we confirmed the coexpression of VGluT2 and TH protein (Fig. 3B). We found a clear decrease in VGluT2 protein levels at P45 when compared with $\mathrm{P} 0$, which is in line with the age-dependent decrease in both VGluT2 mRNA levels and percentage of DA neurons expressing VGluT2 mRNA.

To confirm the presence of VGluT2 mRNA in DA neurons in situ, we collected the cytoplasm of GFP-positive neurons in horizontal slices prepared from the ventral mesencephalon of P14 TH-GFP heterozygous mice. GFP-positive neurons from the VTA and SN were patch clamped in the whole-cell configuration and their cytoplasm was collected by aspiration. Under these conditions, we found $17 \%$ (3 of 18) of DA neurons expressing VGluT2 mRNA. Of these, two were from the VTA whereas one was from the SN (Fig. 4A). Here again, none of the DA neurons 
Table 1. Expression profile of VGluTs in dopamine neurons

\begin{tabular}{|c|c|c|c|c|c|c|}
\hline & & TH/GFP & VGluT1/TH & VGluT2/TH & VGluT3/TH & VGluT2/TH- \\
\hline \multirow[t]{2}{*}{ Acutely dissociated } & P0 & $74 \%$ (68 of 92$)$ & $0 \%(0$ of 68$)$ & $25 \%$ (17 of 68$)$ & $0 \%$ (0 of 68) & $12 \%$ (3 of 24$)$ \\
\hline & P45 & $87 \%$ (58 of 67$)$ & $0 \%(0$ of 56$)$ & $14 \%$ (8 of 58 ) & $0 \%(0$ of 56$)$ & $0 \%(0$ of 9$)$ \\
\hline \multirow[t]{2}{*}{ Slices } & VTA & $61 \%$ (11 of 18$)$ & $0 \%(0$ of 11$)$ & $18 \%$ (2 of 11$)$ & $0 \%$ (0 of 11$)$ & $14 \%$ (1 of 7 ) \\
\hline & SN & $58 \%$ (7 of 12$)$ & $0 \%(0$ of 7$)$ & $14 \%$ (1 of 7 ) & $0 \%(0$ of 7$)$ & $20 \%$ (1 of 5 ) \\
\hline
\end{tabular}

A

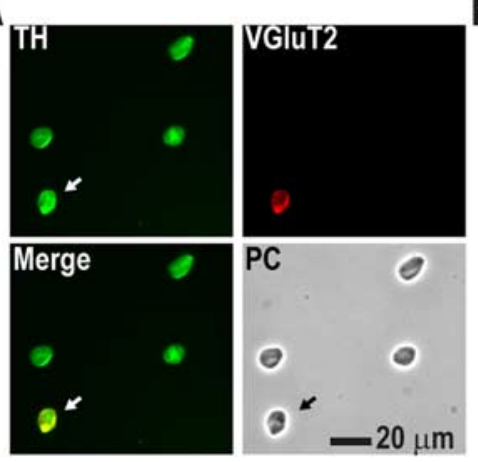

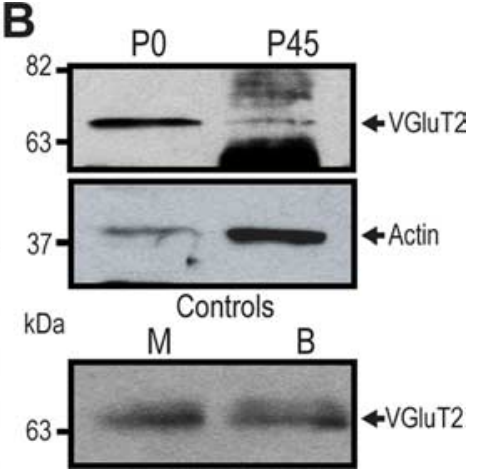

Figure 3. VGluT2 protein is expressed by DA neurons. $\boldsymbol{A}$, Freshly dissociated neurons plated on PEl-coated coverslips were subjected to immunochemistry to detect the expression of VGluT2 protein (red) in TH + (green) neurons from P45 mice. Note the presence of one dually labeled neuron in the field of view (arrow). PC, Phase contrast. B, Comparison of VGluT2 expression by Western blot in FACS-purified DA neurons from P0 and P45 mice. Unidentified additional bands were observed in tissue from P45 mice but never in P0 tissue. M, Whole-mesencephalon extract; $B$, whole-brain extract.

were positive for VGluT1 or VGluT3 (data not shown), thus confirming our initial findings. As in our experiments with freshly dissociated cells, we also found a small contingent of THnegative neurons expressing VGluT2 (2 of 12, one in each nucleus). The results of all RT-PCR phenotyping experiments in acute slices are summarized in Table 1 (bottom two rows). All of the single cells were GAD-67- and GFAP-negative (data not shown).

Finally, the glutamatergic phenotype of DA neurons was confirmed in unperturbed tissue by immunohistochemistry. To do this, we took advantage of a recently developed transgenic mouse expressing a BAC vector carrying the genomic DNA for VGluT2, in which the protein coding sequence was replaced by sequences encoding the EGFP reporter gene. Double immunohistochemistry against TH and GFP, performed on mesencephalic tissue obtained from P0, P10, and P45 mice, revealed the expression of GFP in neurons within the VTA and the SN (supplemental Fig. 1, available at www.jneurosci.org as supplemental material) as well as in several other nuclei where VGluT2 expression has been demonstrated previously, for instance, in the thalamus, mammillary nucleus, and medial geniculate body (Fremeau et al., 2001; Ziegler et al., 2002) (supplemental Fig. 2, available at www. jneurosci.org as supplemental material). Importantly, GFP expression was detected in a small subset of $\mathrm{TH}+$ neurons in both VTA and SN (Fig. 4B). The developmental profile shows again a decrease in the proportion of double-labeled neurons. These results confirm that a subset of DA neurons express VGluT2 in vivo.

\section{Contact with GABA and DA neurons negatively regulates VGluT2 expression in mesencephalic DA neurons}

Our finding that $\sim 20 \%$ of mouse DA neurons in situ express VGluT2 stands in apparent contradiction with a previous observation that $\sim 75 \%$ of rat DA neurons express VGluT2 when they are grown alone in a microculture system (Dal Bo et al., 2004). We hypothesize that VGluT2 expression is upregulated in iso- lated DA neurons growing in microculture because a negative regulatory signal is reduced or absent when neurons develop under such conditions. To begin exploring the factors regulating VGluT2 expression in DA neurons, we compared microcultures to standard cultures in which a large number of DA neurons grow together with other mesencephalic neurons, most of which are GABAergic. Semiquantitative RT-PCR analysis of standard cultures shows no notable variation in VGluT2 mRNA levels over time (Fig. 5A). In contrast, immunocytochemistry shows that there is a gradual increase in the proportion of isolated DA neurons in microculture expressing VGluT2 over time (Fig. $5 B)$. We next used single-cell RT-PCR to compare the proportion of DA neurons expressing VGluT2 mRNA in standard cultures and in microcultures. At $10 \mathrm{~d}$ in culture (Fig. 5 C), we found that $92 \%$ of isolated DA neurons growing in microculture expressed VGluT2 mRNA (33 of 36), whereas when DA neurons were growing in the presence of a large number of other neurons in standard cultures, this proportion dropped dramatically to $14 \%$ ( 10 of 70 ), a value that is very close to the proportion found in acutely dissociated neurons and in situ in brain slices. Interestingly, when DA neurons were growing in contact with at least one other nonidentified neuron in microcultures, the relative expression of VGluT2 dropped from 92 to $48 \%$ (12 of 25). These findings are compatible with the idea that interaction with other neurons acts as a negative regulator of VGluT2 expression by DA neurons.

The negative regulation of VGluT2 expression in DA neurons could occur as a result of interactions with GABA neurons (Johnson and North, 1992; Steffensen et al., 1998), other DA neurons, or both. To test this, we prepared standard cultures from FACSpurified DA neurons and used single-cell RT-PCR to evaluate VGluT2 expression. In such pure DA neuron cultures, we found that $45.1 \pm 11.5 \%$ of DA neurons (24 of 53) contained VGluT2 mRNA (Fig. $5 C$ ), a proportion almost threefold higher than in standard cultures containing both GABA and DA neurons (17.3 $\pm 3.7 \%)$, but lower than in single DA neuron microcultures $(92.5 \pm 9.6 \%)$. This finding suggests that, although not sufficient to completely repress the glutamatergic phenotype of DA neurons, interaction with other DA neurons could provide part of the negative regulatory signal. A similar proportion of DA neurons expressing VGluT2 $(42.5 \pm 7.9 \%)$ was obtained even when the cell density of the FACS-purified cells was decreased fivefold, suggesting that the negative regulation resulting from interaction with DA neurons is not linearly graded as a function of contact density.

We next evaluated whether an interaction with GABA neurons regulates VGluT2 expression in DA neurons. To test this 
A

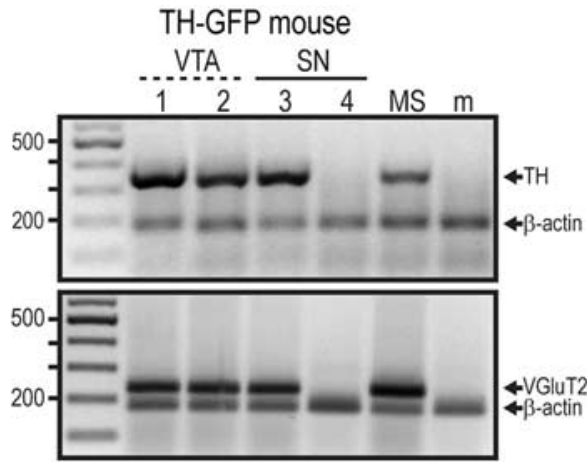

B
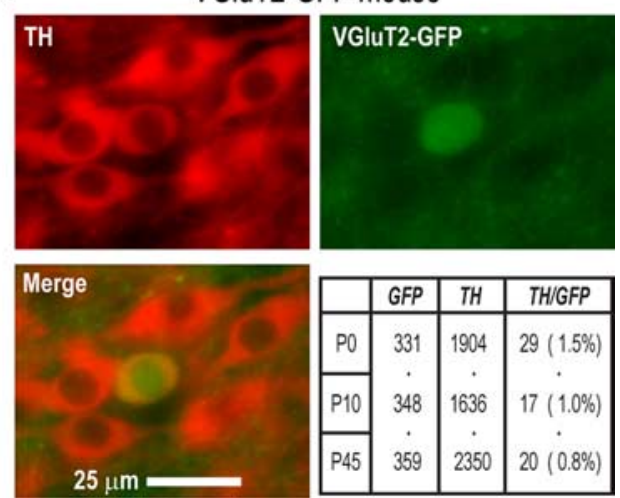

Figure 4. VGluT2 is expressed in DA neurons in situ. $A$, The presence of VGluT2 mRNA in DA neurons in situ was evaluated by single-cell RT-PCR after whole-cell patch-clamp recording from horizontal slices prepared from P14 TH-GFP heterozygous mice. The expression profile of four representative GFP-expressing neurons collected from the VTA (cells 1-2) and SN (cells $3-4$ ) is shown. The presence of TH and $\beta$-actin mRNA was first determined (top), whereas the presence of VGluT2 mRNA was subsequently evaluated in the same samples (bottom). Note that cell 4 expressed neither TH nor VGluT2. The position of collected cells was monitored by loading neighboring neurons with biocytin and post hoc immunohistochemistry against TH and biocytin (data not shown). MS, Whole mesencephalon plus striatum; $m$, muscle. $\boldsymbol{B}$, The expression of GFP driven by the VGluT2 promoter was evaluated at different postnatal ages using VGluT2EGFP BAC transgenic mice. TH (red) and GFP (green) expression was analyzed by double immunocytochemistry in $40 \mu \mathrm{m}$ coronal sections covering the entire mesencephalon. Pictures of randomly selected regions within both SN and VTA were taken. As can be seen in the table at the bottom right, double-labeled neurons were found at all ages tested, with a clear decrease at older ages. A representative double-labeled neuron at P45 is shown. In this experiment, sections prepared from nontransgenic mice were used as negative controls (data not shown).

hypothesis we took advantage of triple-labeling immunocytochemistry to monitor expression of VGluT2 in microcultures containing a single DA neuron (identified by $\mathrm{TH}$ immunoreactivity) together with one or more GABA neuron (identified by GABA immunoreactivity). We found that the presence of a GABA neuron in such microcultures almost completely inhibited the expression of VGluT2 by DA neurons: only one of 19 DA neurons growing under such conditions expressed VGluT2 (Fig. $6 A)$. No such inhibition was seen in microcultures containing just two DA neurons: VGluT2 expression could be detected in at least one of the two neurons in all 24 cases evaluated (Fig. $6 B$ ). Interestingly, the ability of GABA neurons to inhibit VGluT2 expression in DA neurons was selective because we could detect single glutamatergic, non-TH neurons, growing together with a GABA neuron (16 of 16) (Fig. 6C). Together, these findings show that interaction with GABA neurons is particularly effective as a negative regulator of VGluT2 expression in DA neurons.

The signal regulating VGluT2 expression in DA neurons could be a soluble factor released by other neurons. Alternately, it
A

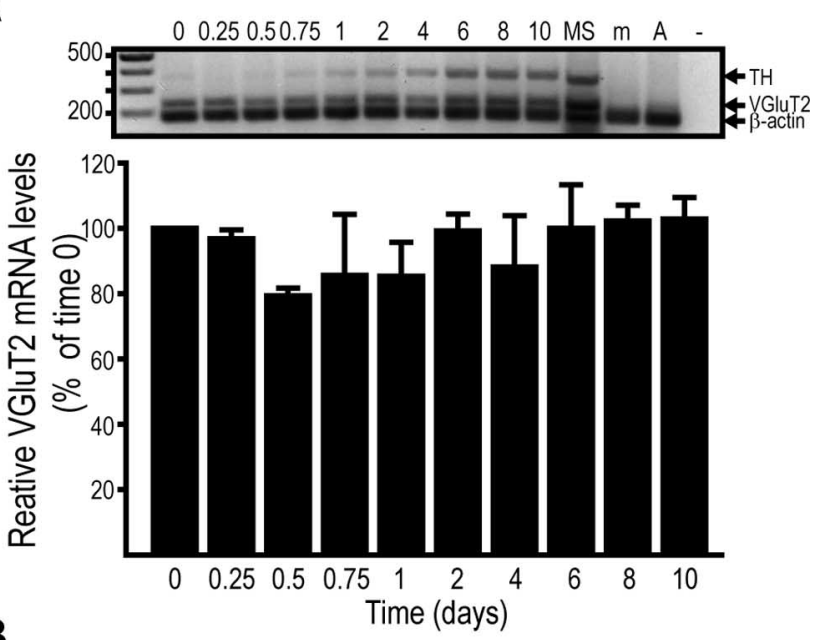

B

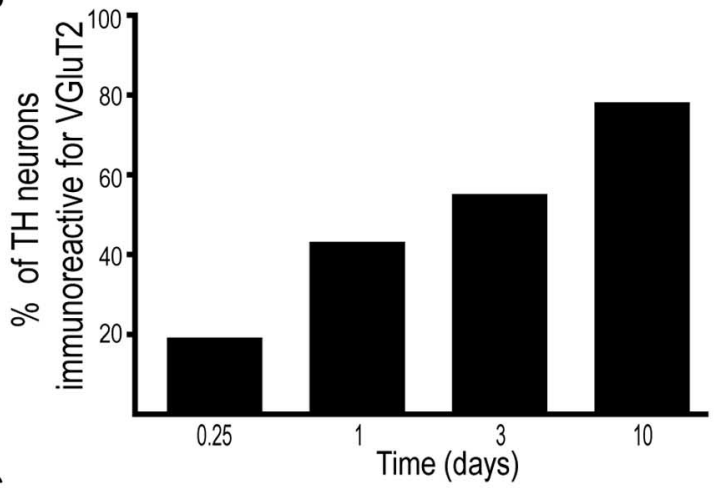

C

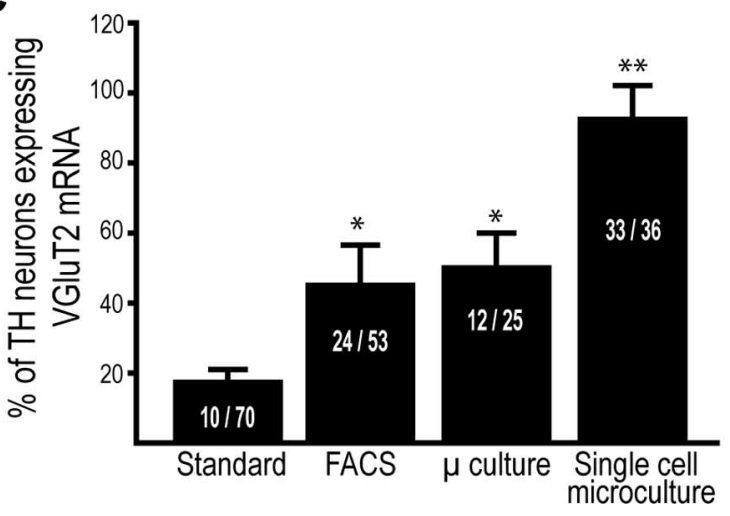

Figure 5. Neuronal interactions regulate VGluT2 expression in DA neurons. $A$, Time course of relative VGluT2 mRNA levels over $10 \mathrm{~d}$ in standard cultures. Time 0 represents the $P 0$ mesencephalic cell suspension before plating and is used as reference. The other samples indicate post plating times. MS, Mesencephalon plus striatum; $m$, muscle; $A$, cultured astrocytes. The bar graph illustrates the relative levels of VGluT2 mRNA normalized against the levels of $\beta$-actin from three experiments. $\boldsymbol{B}$, Time course of the proportion of isolated DA neurons growing in microculture expressing VGluT2 protein measured by immunofluorescence. $C$, Effect of neuronal interactions on the expression of VGluT2 mRNA in cultured DA neurons. Single-cell RT-PCR was performed on the cytoplasm of GFPpositive neurons collected from microcultures (isolated cells), DA neurons growing in microculture together with one or two additional neurons ( $\mu$ culture), DA neurons growing in standard mass cultures (standard), or FACS-purified DA neurons growing in standard cultures (FACS). The graph presents the proportion of TH + DA neurons that expressed VGluT2 mRNA (from at least 4 different experiments). Numbers inside the bars represent the total number of cells analyzed. ${ }^{*} p<0.05$; ${ }^{* *} p<0.01$ versus standard. Error bars indicate SD.

could be a contact-dependent signal mediated by cell-adhesion molecules or other local regulatory signals, or by a combination of secreted and contact-dependent signals. We reasoned that if a secreted factor was involved, growing a microculture for up to 

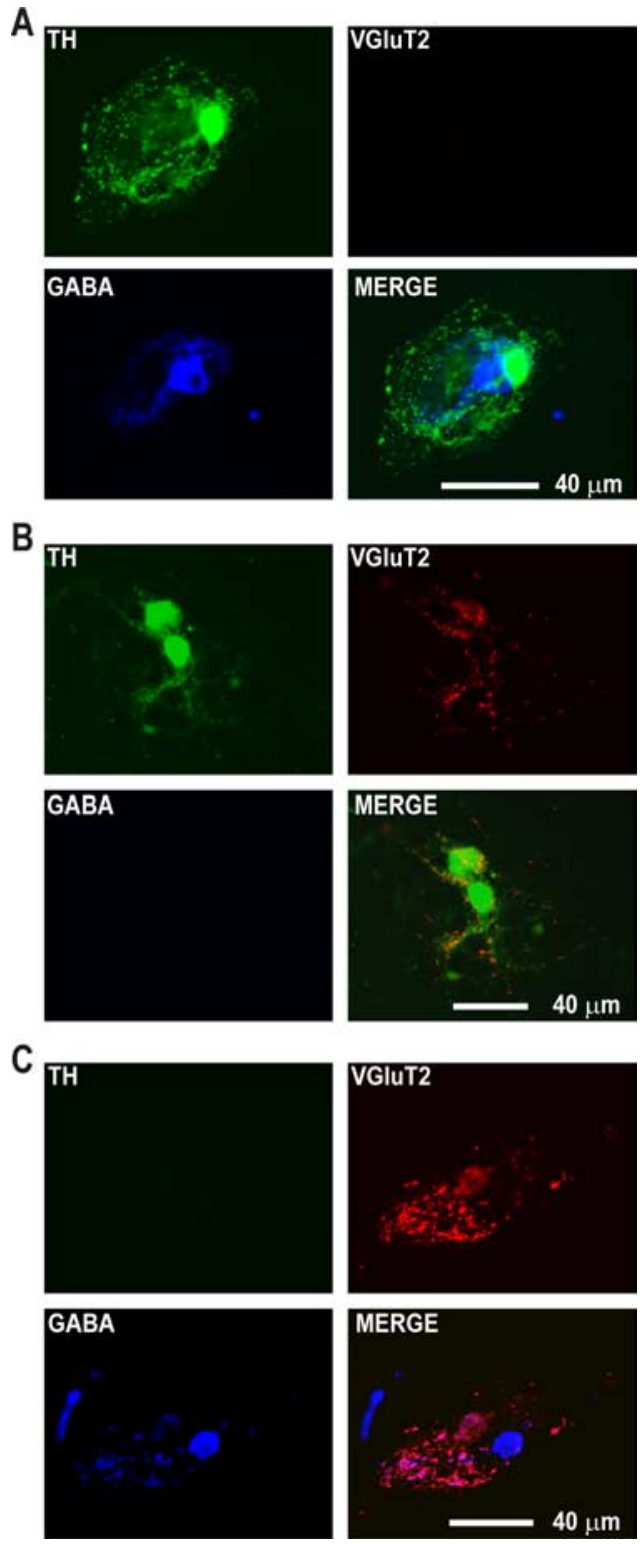

Figure 6. Effect of cell interaction on the expression of VGluT2 in DA neurons. A triplelabeling protocol was used to localize TH (green), VGluT2 (red), and GABA (blue) in mesencephalic neurons in microculture. $\boldsymbol{A}, \boldsymbol{B}$, Whereas interaction of DA neurons with GABA neurons inhibits the expression of VGluT2 by DA neurons (note the absence of VGluT2-immunoreactivity when a single DA neuron is growing together with a GABA-positive neuron) ( $\boldsymbol{A})$, VGluT2 protein can be detected in a microculture containing two DA neurons $(\boldsymbol{B})$. $\boldsymbol{C}$, However, GABA neuron interaction has no effect on non-DA glutamatergic neurons because it is possible to detect microcultures in which a TH-negative VGluT2-positive glutamatergic neuron grows together with a GABA-positive neuron. Micrographs are representative of cells from several coverslips originating from five independent experiments.

$10 \mathrm{~d}$ in the presence of a coverslip containing a standard culture, therefore conditioning the medium, should decrease the proportion of single DA neurons expressing VGluT2. Arguing against the implication of a secreted diffusible factor, we found that the proportion of isolated DA neurons expressing VGluT2 in microcultures grown under such conditions increased over time to reach $77.3 \pm 2.5 \%$ after $10 \mathrm{~d}$ (Fig. $7 A$ ). This proportion is similar to that obtained for microcultures growing alone $(92.5 \pm 9.5 ; p>$ $0.05)$. Moreover, chronic treatment of microcultures with exogenous GABA $(100 \mu \mathrm{M})$ during $10 \mathrm{~d}$ failed to inhibit VGluT2 expression in single DA neurons (Fig. $7 B$ ), thus showing that the
A

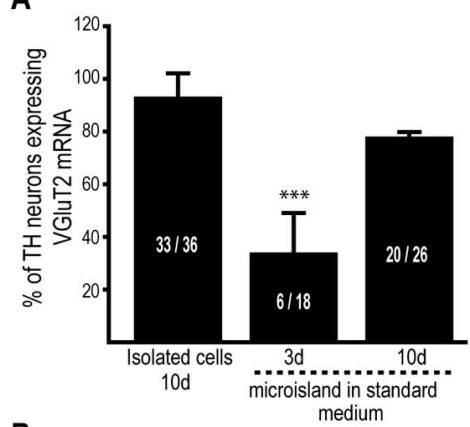

B

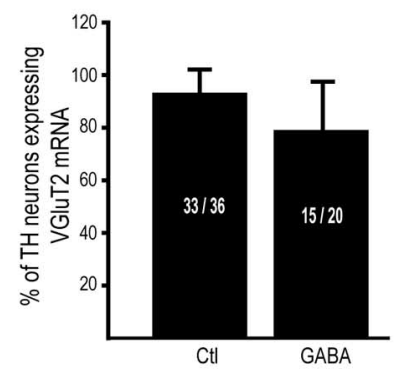

C

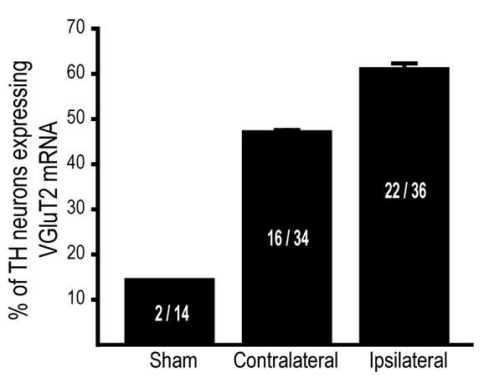

Figure 7. Repression of the glutamatergic phenotype of DA neurons requires cell contact with GABA neurons. $A$, The impact of conditioned standard culture medium on VGluT2 mRNA expression in isolated DA neurons growing in microculture was evaluated by single-cell RT-PCR. The graph represents the proportion of TH + isolated neurons expressing VGluT2 mRNA after 3 or $10 \mathrm{~d}$ in the presence of culture medium conditioned by the presence of a second coverslip containing a standard mass culture (microisland in standard medium). Numbers inside the bars represent the total number of neurons analyzed from at least four different experiments. ${ }^{* * *} p<0.001$ versus isolated cells at $10 \mathrm{~d}$. $\boldsymbol{B}$, Effect of chronic GABA treatment on VGluT2 mRNA expression in isolated $D A$ neurons growing in microculture. DA neurons grown in microcultures were chronically treated with $100 \mu \mathrm{M}$ GABA during $10 \mathrm{~d}$. After this, isolated GFP-expressing neurons were collected and their cytoplasm subjected to singe-cell RT-PCR to determine the proportion of DA neurons that expressed VGluT2. The graph shows no significant differences versus control conditions. Numbers inside the bars represent the total number of neurons analyzed from at least four different experiments. C, Effect of striatal QA lesions on VGluT2 expression by DA neurons. Lesion of striatal GABA neurons with QA induced an increase in the proportion of mesencephalic DA neurons containing VGluT2 mRNA both ipsilaterally and contralaterally to the striatal lesion compared with sham controls. Error bars indicate SD.

inhibition of the glutamatergic phenotype is not related to the effects of GABA released by the GABAergic neurons.

In light of our results showing that, in culture, interaction with GABAergic neurons downregulates the expression of VGluT2 in DA neurons, a prediction is that perturbation of the GABAergic striatonigral pathway in vivo could cause an upregulation of VGluT2 expression in midbrain DA neurons. To test this possibility, we used QA to perform unilateral lesions of the dorsomedial area of the striatum in TH-GFP mice (supplemental Fig. 3, available at www.jneurosci.org as supplemental material). This excitotoxin is known to cause selective degeneration of GABAergic neurons projecting to the $\mathrm{SN}$, although sparing DA axons, therefore reducing the number of GABAergic contacts received 
by DA neurons. In addition, it can induce transneuronal death of local GABAergic neurons of the SN pars reticulata (Macaya et al., 1994). We found that $5 \mathrm{~d}$ after QA striatal lesions in P10 pups, there was a notable decrease in the number of GABAimmunoreactive neurons and processes in the dorsolateral part of the lesioned striatum (supplemental Fig. 3, available at www. jneurosci.org as supplemental material). This was accompanied by an increase in S100-immunopositive astrocytic processes, compatible with lesion-associated glial activation (supplemental Fig. 3, available at www.jneurosci.org as supplemental material). Acute dissociation of mesencephalic DA neurons from these animals followed by single-cell RT-PCR revealed that ipsilateral to the lesion, there was a fourfold increase in the proportion of DA neurons expressing VGluT2 compared with the Sham animals (Fig. 7C). This was also accompanied by a threefold induction on the contralateral side.

We thus conclude that VGluT2 expression in DA neurons is tightly regulated by interaction with GABAergic neurons through a mechanism that is likely to depend on contact-dependent signals.

\section{Discussion}

In recent years, a paradox has evolved with regards to the signals mediated by DA neurons in vivo. Although it is well accepted that DA neurons encode motivational changes, reward predictions, or stimulus salience via fast transient neuronal activity (Schultz, 1998; Schultz and Dickinson, 2000), their slow postsynaptic signaling through DA and its G-protein-coupled receptors are not very well suited to mediate fast signals. The ability of a subset of DA neurons to use a fast-acting neurotransmitter as cotransmitter may shed light on this apparent paradox. Interestingly, previous reports showed that electrical stimulation of the VTA induces fast glutamate-mediated EPSCs in target areas (Chuhma et al., 2004; Lavin et al., 2005). We now provide an explanation for this remarkable capability by demonstrating that a subset of mesencephalic DA neurons of the SN and VTA selectively expresses the vesicular glutamate transporter VGluT2. Moreover, we show that VGluT2 expression by DA neurons is under tight regulatory control by GABA and DA neurons. These data provide novel evidence that the neurotransmitter phenotype of DA neurons is plastic during the early postnatal period.

\section{Glutamate as a cotransmitter in DA neurons}

We previously provided an explanation for the capacity of cultured DA neurons to release glutamate by showing that rat mesencephalic DA neurons in culture express VGluT2 (Dal Bo et al., 2004). This finding provides solid evidence of corelease because expression of a VGluT is sufficient to provide a neuron the capacity to release glutamate at synaptic contacts (Takamori et al., 2000, 2001). However, the expression of VGluTs in DA neurons in vivo has remained controversial. Whereas initial in situ hybridization studies failed to detect VGluT transcripts in the ventral mesencephalon (Fremeau et al., 2001; Gras et al., 2002; Schafer et al., 2002; Herzog et al., 2004) (but see Fremeau et al., 2002), a recent in situ hybridization study, Kawano et al. (2006) showed that VGluT2 mRNA is found in a small subset of DA neurons of the medial nuclei of the A10 cell group in adult rats. Another similar study reported only very few DA neurons coexpressing VGluT2 in the adult VTA (Yamaguchi et al., 2007). In contrast, we show here that $\sim 15 \%$ of acutely dissociated DA neurons or DA neurons in acute brain slices contain VGluT2 mRNA. Moreover, we found such coexpression of VGluT2 and TH not only in the VTA, but also in the SN. The discrepancy between the in situ hybridization studies and the current work may result from the fact that in situ hybridization is not as sensitive as single-cell RT-PCR to detect low mRNA copy number. Additionally, given that the expression of VGluT2 rapidly decreases after birth, the difficulty to detect VGluT2 mRNA in DA neurons in previous reports could be caused by the fact that only adult animals were examined. Under our experimental conditions, we were unable to find any evidence for the expression of VGluT1 or VGluT3 mRNAs in mesencephalic DA neurons. Although one could argue that the expression of these transcripts is simply too low to be reliably detected, we can discount this possibility because even when using a higher number of PCR cycles, we failed to detect them. Moreover, we easily detected these transcripts in neurons isolated from the cerebral cortex or raphe nucleus.

VGluT2 expression in DA neurons is not likely to be a feature specific to TH-GFP transgenic mice because DA neurons from wild-type mice of the same genetic background also contain VGluT2 mRNA in proportions similar to those found in TH-GFP mice (supplemental Fig. 4, available at www.jneurosci.org as supplemental material). In addition, expression of VGluT2 in DA neurons was confirmed by using the novel VGluT2-EGFP BAC transgenic mouse at different postnatal ages. Although the percentage of TH/GFP double-labeled neurons detected by immunohistochemistry in these mice was substantially lower than what might have been predicted by single-cell RT-PCR experiments, the age-dependent decrease in the double phenotype of DA neurons was proportionally similar to that found in our other experiments. This difference perhaps results from the limited sensitivity of immunohistochemistry compared with RT-PCR. Moreover, the abundant GFP signal originating from axonal and dendritic processes in the ventral mesencephalon made it frequently difficult to distinguish cell bodies expressing low GFP levels from background signal (supplemental Fig. 1, available at www.jneurosci.org as supplemental material).

\section{Existence of a subpopulation of glutamatergic neurons in the VTA/SN}

In line with previous reports (Dal Bo et al., 2004; Hur and $\mathrm{Za}$ borszky, 2005; Kawano et al., 2006; Yamaguchi et al., 2007), using single-cell RT-PCR we detected a subpopulation of purely glutamatergic (i.e., not expressing TH) neurons in the VTA/SN region. We detected them in freshly dissociated neurons at $\mathrm{P} 0$ as well as in acute VTA/SN horizontal brain slices prepared from P14 THGFP and VGluT2-EGFP mice (supplemental Fig. 1, available at www.jneurosci.org as supplemental material). Considering the presence of such a pure glutamatergic population within the mesencephalon and the existence of a retrograde-labeling study reporting the identification of glutamatergic projections arising from the VTA to the PFC (Hur and Zaborszky, 2005), it could be argued that glutamate-induced EPSCs evoked in PFC neurons by VTA stimulation (Lavin et al., 2005) could be mediated by pure glutamatergic neurons instead of DA neurons. However, such fast responses in PFC in response to VTA stimulation were reported to be prevented by a 6-OHDA lesion of VTA DA neurons. Additional experiments will be required to characterize the anatomical and physiological properties of VTA/SN purely glutamatergic neurons.

\section{The neurotransmitter phenotype of DA neurons is regulated during development and through cell contact}

Our finding that the proportion of DA neurons expressing VGluT2 decreases with age provides a plausible explanation for the sparse expression of VGluT2 in VTA DA neurons reported in 
adult rats (Yamaguchi et al., 2007). The biological significance of this developmental phenotypic regulation is presently unexplored. However, because DA itself is not necessary for the development of the nigrostriatal pathway (Zhou and Palmiter, 1995) and metabotropic glutamate receptor antagonists decrease synapse formation by DA neurons (Plenz and Kitai, 1998), it is possible that glutamate released by DA neurons contributes to the development and fine tuning of dopaminergic pathways.

Interestingly, interactions with other neurons, in particular with GABA neurons, strongly inhibit VGluT2 expression by DA neurons. Because GABAergic contacts with DA neurons are established during late embryonic phases and continue to develop during the first postnatal weeks (Voorn et al., 1988; Fishell and van der Kooy, 1989), the developmental disappearance of VGluT2 in DA neurons could be explained in part by a negative regulation exerted by interactions with local and projecting GABA neurons, as they develop gradually. In support of this hypothesis, we found an induction or derepression of VGluT2 expression in DA neurons in mice in which GABAergic projections to DA neurons were reduced by a QA lesion. This adaptive response of DA neurons can be seen as a novel form of functional plasticity. Although additional studies are required to identify the specific contact-dependent signals involved, our observations provide an explanation for the fact that, although the majority of DA neurons express VGluT2 when grown in isolation, only a subset expresses it when growing under conditions allowing them to establish interactions with other mesencephalic neurons. Unexpectedly, in the QA lesion experiments, we also found an important increase in the proportion of DA neurons expressing VGluT2 on the side contralateral to the lesion (Fig. 7C). One possibility is that this results from denervation of the crossed striatal-nigral projection (Loughlin and Fallon, 1982; Altar et al., 1983), leading to a decrease in the GABAergic input received by contralateral DA neurons.

Although contact with GABA neurons appears to play a key role, we found that in FACS-purified DA neuron cultures, the proportion of DA neurons expressing VGluT2 was higher than in standard mixed cultures, but not as high as in microcultures where DA neurons grow in isolation. Because the GABAbiosynthetic enzyme GAD could not be detected in FACSpurified cells (Fig. 1D), other DA neurons could also provide a negative regulatory signal leading to partial inhibition of VGluT2 expression by DA neurons. Moreover, because QA lesions have the potential to induce apoptosis in a subset of developing DA neurons (Macaya et al., 1994), it is possible that a reduction in DA neurons may have indirectly contributed to the increase in the proportion of DA neurons expressing VGluT2 after the lesion. Nonetheless, when considered in the context of our in vitro results, it remains more likely that the increased expression of VGluT2 in DA neurons is a direct result of the death of striatal GABA neurons.

Direct chronic exposure of microcultures to exogenous GABA $(100 \mu \mathrm{M})$ failed to inhibit VGluT2 expression in isolated DA neurons in microculture (Fig. $7 B$ ), suggesting that, at least in vitro, GABAergic transmission per se is not implicated in the regulation of VGluT2 expression in DA neurons. Finally, considering the lack of effect of conditioned culture medium, the involvement of secreted factors in the repression of VGluT2 is unlikely. However, we do not exclude the possibility that secreted signals such as growth factors may act as additional regulators of VGluT2 expression in DA neurons, as suggested by the ability of glial cell line-derived neurotrophic factor to increase glutamate release by cultured DA neurons (Bourque and Trudeau, 2000).
Our work suggests that a perturbation of the developmental program of DA neurons or of the GABAergic inputs to these cells could lead to an upregulation or downregulation of glutamate cotransmission, leading to perturbations of mesotelencephalic circuits and of cortical processing. The present work thus sets the stage for additional studies aimed at identifying specific roles of glutamate cotransmission in the various physiological functions of VTA/SN DA neurons, its possible plasticity in the adult, and whether glutamate cotransmission is implicated in diseases such as Huntington's, Parkinson's, schizophrenia, and drug dependence that are associated with dysfunctional basal ganglia circuits.

\section{References}

Aihara Y, Mashima H, Onda H, Hisano S, Kasuya H, Hori T, Yamada S, Tomura H, Yamada Y, Inoue I, Kojima I, Takeda J (2000) Molecular cloning of a novel brain-type $\mathrm{Na}(+)$-dependent inorganic phosphate cotransporter. J Neurochem 74:2622-2625.

Altar A, Neve KA, Loughlin SE, Marshall JF, Fallon JH (1983) The crossed mesostriatal projection: neurochemistry and developmental response to lesion. Brain Res 279:1-8.

Borodinsky LN, Root CM, Cronin JA, Sann SB, Gu X, Spitzer NC (2004) Activity-dependent homeostatic specification of transmitter expression in embryonic neurons. Nature 429:523-530.

Bourque MJ, Trudeau LE (2000) GDNF enhances the synaptic efficacy of dopaminergic neurons in culture. Eur J Neurosci 12:3172-3180.

Chuhma N, Zhang H, Masson J, Zhuang X, Sulzer D, Hen R, Rayport S (2004) Dopamine neurons mediate a fast excitatory signal via their glutamatergic synapses. J Neurosci 24:972-981.

Dal Bo G, St-Gelais F, Danik M, Williams S, Cotton M, Trudeau LE (2004) Dopamine neurons in culture express VGLUT2 explaining their capacity to release glutamate at synapses in addition to dopamine. J Neurochem 88:1398-1405

Danik M, Puma C, Quirion R, Williams S (2003) Widely expressed transcripts for chemokine receptor CXCR1 in identified glutamatergic, gamma-aminobutyric acidergic, and cholinergic neurons and astrocytes of the rat brain: a single-cell reverse transcription-multiplex polymerase chain reaction study. J Neurosci Res 74:286-295.

Danik M, Cassoly E, Manseau F, Sotty F, Mouginot D, Williams S (2005) Frequent coexpression of the vesicular glutamate transporter 1 and 2 genes, as well as coexpression with genes for choline acetyltransferase or glutamic acid decarboxylase in neurons of rat brain. J Neurosci Res 81:506-521.

Fishell G, van der Kooy D (1989) Pattern formation in the striatum: developmental changes in the distribution of striatonigral projections. Brain Res Dev Brain Res 45:239-255.

Fremeau Jr RT, Troyer MD, Pahner I, Nygaard GO, Tran CH, Reimer RJ, Bellocchio EE, Fortin D, Storm-Mathisen J, Edwards RH (2001) The expression of vesicular glutamate transporters defines two classes of excitatory synapse. Neuron 31:247-260.

Fremeau Jr RT, Burman J, Qureshi T, Tran CH, Proctor J, Johnson J, Zhang H, Sulzer D, Copenhagen DR, Storm-Mathisen J, Reimer RJ, Chaudhry FA, Edwards RH (2002) The identification of vesicular glutamate transporter 3 suggests novel modes of signaling by glutamate. Proc Natl Acad Sci USA 99:14488-14493.

Gillespie DC, Kim G, Kandler K (2005) Inhibitory synapses in the developing auditory system are glutamatergic. Nat Neurosci 8:332-338.

Gomez-Lira G, Lamas M, Romo-Parra H, Gutierrez R (2005) Programmed and induced phenotype of the hippocampal granule cells. J Neurosci 25:6939-6946.

Gong S, Zheng C, Doughty ML, Losos K, Didkovsky N, Schambra UB, Nowak NJ, Joyner A, Leblanc G, Hatten ME, Heintz N (2003) A gene expression atlas of the central nervous system based on bacterial artificial chromosomes. Nature 425:917-925.

Gras C, Herzog E, Bellenchi GC, Bernard V, Ravassard P, Pohl M, Gasnier B, Giros B, El Mestikawy S (2002) A third vesicular glutamate transporter expressed by cholinergic and serotoninergic neurons. J Neurosci 22:5442-5451.

Gutierrez R (2000) Seizures induce simultaneous GABAergic and glutamatergic transmission in the dentate gyrus-CA3 system. J Neurophysiol 84:3088-3090. 
Herzog E, Gilchrist J, Gras C, Muzerelle A, Ravassard P, Giros B, Gaspar P, El Mestikawy S (2004) Localization of VGLUT3, the vesicular glutamate transporter type 3, in the rat brain. Neuroscience 123:983-1002.

Holton P (1959) The liberation of adenosine triphosphate on antidromic stimulation of sensory nerves. J Physiol (Lond) 145:494-504.

Hur EE, Zaborszky L (2005) Vglut2 afferents to the medial prefrontal and primary somatosensory cortices: a combined retrograde tracing in situ hybridization. J Comp Neurol 483:351-373.

Johnson SW, North RA (1992) Two types of neurone in the rat ventral tegmental area and their synaptic inputs. J Physiol (Lond) 450:455-468.

Jomphe C, Bourque MJ, Fortin GD, St-Gelais F, Okano H, Kobayashi K, Trudeau LE (2005) Use of TH-EGFP transgenic mice as a source of identified dopaminergic neurons for physiological studies in postnatal cell culture. J Neurosci Methods 146:1-12.

Jonas P, Bischofberger J, Sandkuhler J (1998) Corelease of two fast neurotransmitters at a central synapse. Science 281:419-424.

Joyce MP, Rayport S (2000) Mesoaccumbens dopamine neuron synapses reconstructed in vitro are glutamatergic. Neuroscience 99:445-456.

Kawano M, Kawasaki A, Sakata-Haga H, Fukui Y, Kawano H, Nogami H, Hisano S (2006) Particular subpopulations of midbrain and hypothalamic dopamine neurons express vesicular glutamate transporter 2 in the rat brain. J Comp Neurol 498:581-592.

Kay AR, Wong RK (1986) Isolation of neurons suitable for patch-clamping from adult mammalian central nervous systems. J Neurosci Methods $16: 227-238$

Lavin A, Nogueira L, Lapish CC, Wightman RM, Phillips PE, Seamans JK (2005) Mesocortical dopamine neurons operate in distinct temporal domains using multimodal signaling. J Neurosci 25:5013-5023.

Loughlin SE, Fallon JH (1982) Mesostriatal projections from ventral tegmentum and dorsal raphe: cells project ipsilaterally or contralaterally but not bilaterally. Neurosci Lett 32:11-16.

Macaya A, Munell F, Gubits RM, Burke RE (1994) Apoptosis in substantia nigra following developmental striatal excitotoxic injury. Proc Natl Acad Sci USA 91:8117-8121.

Matsushita N, Okada H, Yasoshima Y, Takahashi K, Kiuchi K, Kobayashi K (2002) Dynamics of tyrosine hydroxylase promoter activity during midbrain dopaminergic neuron development. J Neurochem 82:295-304.

Paxinos G, Franklin KBJ (2001) The mouse brain in stereotaxic coordinates, Ed 2. San Diego: Academic.

Plenz D, Kitai ST (1998) Regulation of the nigrostriatal pathway by metabotropic glutamate receptors during development. J Neurosci 18:4133-4144.

Rayport S (2001) Glutamate is a cotransmitter in ventral midbrain dopamine neurons. Parkinsonism Relat Disord 7:261-264.

Sawamoto K, Nakao N, Kobayashi K, Matsushita N, Takahashi H, Kakishita K, Yamamoto A, Yoshizaki T, Terashima T, Murakami F, Itakura T, Okano H (2001) Visualization, direct isolation, and transplantation of midbrain dopaminergic neurons. Proc Natl Acad Sci USA 98:6423-6428.
Schafer MK, Varoqui H, Defamie N, Weihe E, Erickson JD (2002) Molecular cloning and functional identification of mouse vesicular glutamate transporter 3 and its expression in subsets of novel excitatory neurons. J Biol Chem 277:50734-50748.

Schultz W (1998) Predictive reward signal of dopamine neurons. J Neurophysiol 80:1-27.

Schultz W, Dickinson A (2000) Neuronal coding of prediction errors. Annu Rev Neurosci 23:473-500.

Schwarzer C, Sperk G (1995) Hippocampal granule cells express glutamic acid decarboxylase-67 after limbic seizures in the rat. Neuroscience 69:705-709.

Segal MM, Baughman RW, Jones KA, Huettner JE (1998) Mass cultures and microislands of neurons from postnatal rat brain. In: Culturing nerve cells, Ed 2 (Banker G, Goslin K, eds), pp 309-338. Cambridge, MA: MIT.

Steffensen SC, Svingos AL, Pickel VM, Henriksen SJ (1998) Electrophysiological characterization of GABAergic neurons in the ventral tegmental area. J Neurosci 18:8003-8015.

Sulzer D, Joyce MP, Lin L, Geldwert D, Haber SN, Hattori T, Rayport S (1998) Dopamine neurons make glutamatergic synapses in vitro. J Neurosci 18:4588-4602.

Takamori S, Rhee JS, Rosenmund C, Jahn R (2000) Identification of a vesicular glutamate transporter that defines a glutamatergic phenotype in neurons. Nature 407:189-194.

Takamori S, Rhee JS, Rosenmund C, Jahn R (2001) Identification of differentiation-associated brain-specific phosphate transporter as a second vesicular glutamate transporter (VGLUT2). J Neurosci 21:RC182.

Trevino M, Gutierrez R (2005) The GABAergic projection of the dentate gyrus to hippocampal area CA3 of the rat: presynaptic and postsynaptic actions after seizures. J Physiol (Lond) 567:939-949.

Trudeau LE (2004) Glutamate co-transmission as an emerging concept in monoamine neuron function. J Psychiatry Neurosci 29:296-310.

Voorn P, Kalsbeek A, Jorritsma-Byham B, Groenewegen HJ (1988) The prenatal and postnatal development of the dopaminergic cell groups in the ventral mesencephalon and the dopaminergic innervation of the striatum of the rat. Neuroscience 25:857-887.

Yamaguchi T, Sheen W, Morales M (2007) Glutamatergic neurons are present in the rat ventral tegmental area. Eur J Neurosci 25:106-118.

Yang B, Slonimsky JD, Birren SJ (2002) A rapid switch in sympathetic neurotransmitter release properties mediated by the $\mathrm{p} 75$ receptor. Nat Neurosci 5:539-545.

Zaborszky L, Vadasz C (2001) The midbrain dopaminergic system: anatomy and genetic variation in dopamine neuron number of inbred mouse strains. Behav Genet 31:47-59.

Zhou QY, Palmiter RD (1995) Dopamine-deficient mice are severely hypoactive, adipsic, and aphagic. Cell 83:1197-1209.

Ziegler DR, Cullinan WE, Herman JP (2002) Distribution of vesicular glutamate transporter mRNA in rat hypothalamus. J Comp Neurol 448:217229. 